\title{
PERANCANGAN DAN PEMANFAATAN TEKNOLOGI HIDROPONIK VERTIKAL HIDRO 40 HOLE BAGI KARANG TARUNA TRI TUNGGAL DI DESA TALANG PAUH
}

\section{DESIGN AND UTILIZATION OF HYDROPONICS VERTICAL HYDRO 40 HOLES FOR KARANG TARUNA TRI TUNGGAL IN TALANG PAUH VILLAGE}

\author{
Oleh: \\ Halauddin, Supiyati, Suhendra \\ Jurusan Fisika, Fakultas MIPA, Universitas Bengkulu \\ Email: halau_uddin@yahoo.com
}

\begin{abstract}
It has been devoted an activity in community in application of science and technology with the title: Design and Utilization Hydroponic Vertical Hydro 40 Hole for Karang Taruna Tri Tunggal in Talang Pauh Village, Pondok Kelapa District, Central Bengkulu. This dedication destination to design and utilize hydroponic vertical hydro technology as one of the ground breaking technological break throughs in rural areas to complement the vegetable needs for house hold scale. From the results of the implementation of dedication can be concluded that hydroponic technology vertical model of 40 holes hydro can be well received by the participant's devotion. The plant species are mustard, this plant can grow well from two weeks old, although the harvest period for mustard plants is estimated to 35 50 days.
\end{abstract}

Keywords: hydroponic, vertical hydro, 40 hole, house hold scale, Talang Pauh Village

\section{PENDAHULUAN}

Hidroponik merupakan teknik budidaya tanaman tanpa menggunakan media tanah, melainkan menggunakan air sebagai media tanamnya. Sehingga sistem bercocok tanam secara hidroponik dapat memanfaatkan lahan yang sempit. Pertanian dengan menggunakan sistem hidroponik memang tidak memerlukan lahan yang luas dalam pelaksanaannya, tetapi dalam bisnis pertanian hidroponik hanya layak dipertimbangkan mengingat dapat dilakukan di pekarangan rumah, atap rumah maupun lahan lainnya (Mas'ud, 2009).

Hidroponik sendiri dapat dikategorikan menjadi dua, yaitu sistem aktif dan sistem pasif. Hidroponik sistem aktif yaitu dimana larutan air beserta nutrisi dibuat bergerak dan bersirkulasi dengan menggunakan pompa air. Contohnya adalah DFT (Deep Flow Technique), NFT (Nutrient Film Technique), Aeroponik dan Vertikal Hidro. Sedangkan hidroponik sistem pasif yaitu larutan kaya nutrisi diserap oleh medium dan diteruskan ke akar tanaman, tanpa tersirkulasi. Contoh sistem hidroponik pasif antara lain Wick atau sistem sumbu (Triosa, 2016).

\section{Pengertian hidroponik}

Hidroponik (Inggris: hydroponic) berasal dari kata Yunani yaitu hydro yang berarti air dan ponos yang artinya pengerjaan atau bercocok tanam. Hidroponik juga dikenal sebagai soilless culture atau budidaya tanaman tanpa tanah. Jadi, hidroponik adalah 


\section{2}

Dharma Raflesia Unib Tahun XVI, Nomor 1 Juni 2018

budidaya tanaman yang memanfaatkan air tanpa menggunakan tanah sebagai media tanam atau soilless (Syamsu, 2014).

\section{Jenis-jenis sistem hidroponik}

\section{a. Sistem Aeroponic}

Sistem Aeroponic (Gambar 1) merupakan sistem hidroponik yang paling canggih dan kemungkinan dapat memberikan hasil terbaik serta tercepat dalam pertumbuhan dalam berkebun hidroponik.

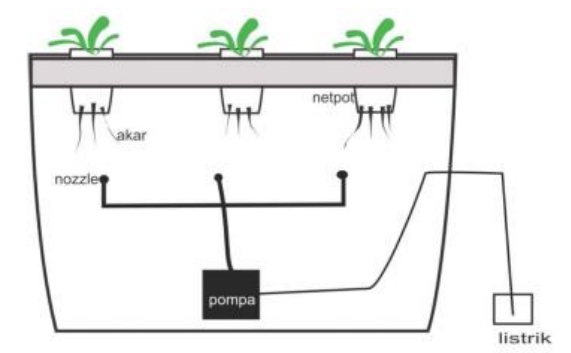

Gambar 1. Hidroponik sistem Aeroponic (Anas, 2013)

Hal ini disebabkan karena larutan nutrisi yang diberikan atau disemprotkan berbentuk kabut langsung ke akar, sehingga akar tanaman lebih mudah menyerap larutan nutrisi yang banyak mengandung oksigen. Sementara tanaman sangat membutuhkan nutrisi dan oksigen dalam pertumbuhannya (Anas, 2013).

\section{b. Sistem EBB dan Flow}

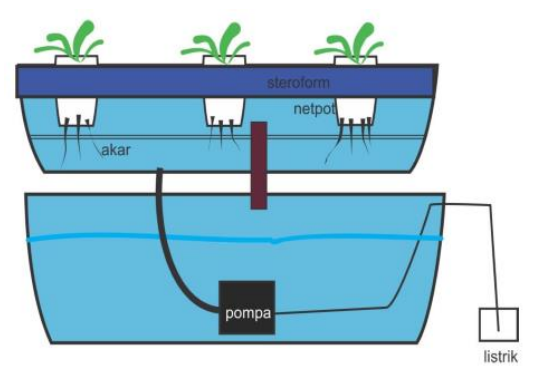

Gambar 2. Hidroponik sistem EBB dan Flow (Anas, 2013)

Sistem EBB dan Flow (Gambar 2) bekerja dengan cara membanjiri sementara wadah pertumbuhan dengan nutrisi sampai air pada batas tertentu, kemudian mengembalikan nutrisi itu ke dalam penampungan, begitu seterusnya. Sistem ini memerlukan pompa yang dikoneksikan ke timer.

\section{c. Sistem tetes (drip system)}

Sistem tetes merupakan sistem hidroponik yang sering digunakan untuk saat ini. Sistem operasinya sederhana yaitu dengan menggunakan timer mengontrol pompa. 


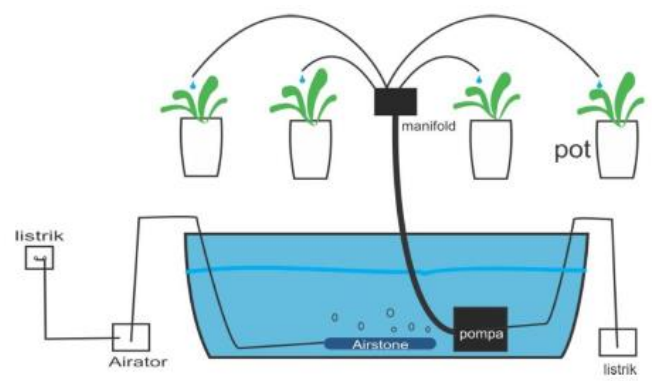

Gambar 3. Hidroponik sistem tetes (Anas, 2013)

Pada saat pompa dihidupkan, pompa meneteskan nutrisi ke masing-masing tanaman. Supaya berdiri tegak, tanaman ditopang menggunakan media tanam lain seperti cocopit, sekam bakar, ziolit, pasir, selain tanah.

\section{d. Sistem NFT (nutrient film technique)}

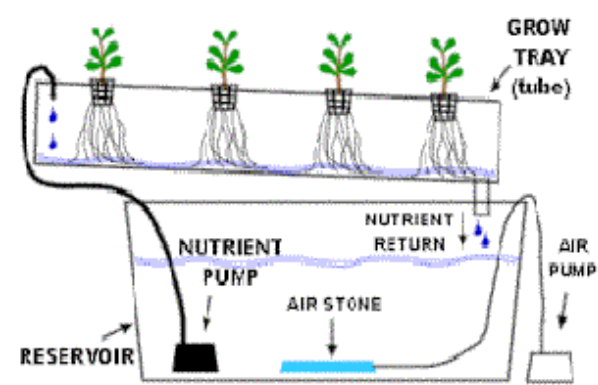

Gambar 4. Hidroponik sistem NFT (Anas, 2013).

Sistem NFT (Gambar 4) adalah cara yang paling populer dalam istilah hidroponik. Sistem ini secara terus menerus mengalirkan nutrisi yang terlarut dalam air tanpa menggunakan timer untuk pompanya. Nutrisi ini akan mengalir ke dalam gully melewati akar-akar tumbuhan dan kemudian kembali lagi ke penampungan air, begitu seterusnya.

\section{e. Sistem water culture}

Water culture (Gambar 5) merupakan sistem hidroponik yang sederhana. Wadah yang menyangga tanaman biasanya terbuat dari sterofoam dan mengapung langsung dengan nutrisi. Pompa udara memompa udara ke dalam air stone yang membuat gelembung-gelembung sebagai suply oksigen ke akar-akar tanaman.

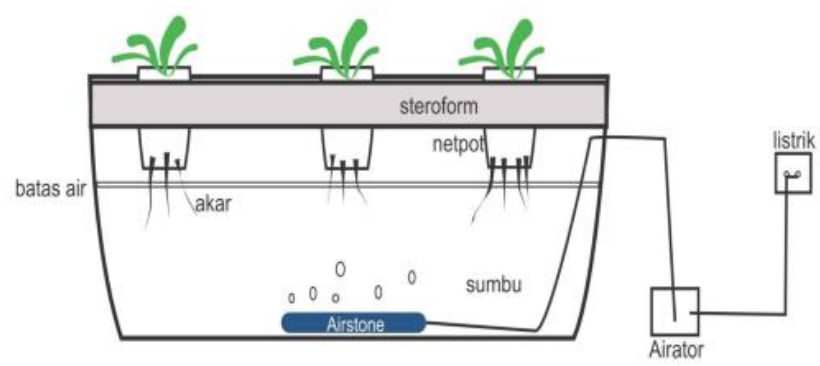

Gambar 5. Hidroponik sistem water culture (Anas, 2013). 


\section{Jenis-jenis media tanam pada sistem hidroponik}

\section{a. Rockwool}

Rockwool (Gambar 6) merupakan salah satu media tanam hidroponik yang paling banyak digunakan oleh petani/penggemar hidroponik khususnya di Indonesia. Rockwool merupakan media tanam anorganik yang berbentuk menyerupai busa, memiliki serabutserabut halus dan bobotnya sangat ringan. Busa ini dibuat dari batuan basalt yang dipanaskan pada suhu tinggi hingga meleleh, kemudian mencair dan terbentuklah seratserat halus.

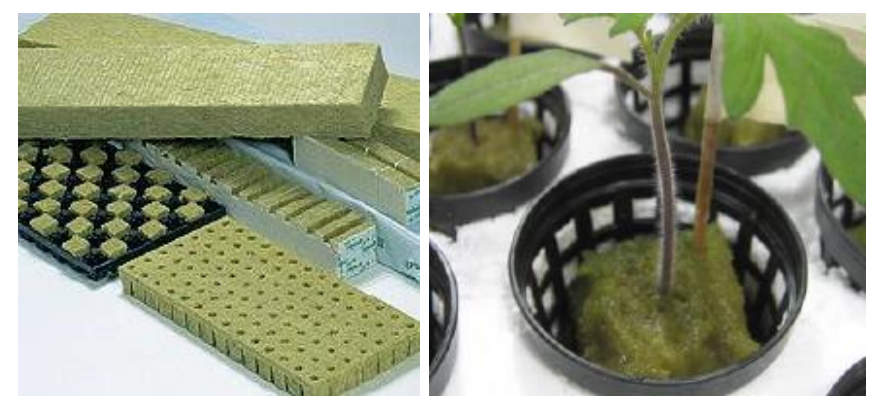

Gambar 6. Penggunaan rockwool dalam budidaya hidroponik (Lingga, 1994).

\section{b. Cocopeat}

Cocopeat (Gambar 7) merupakan media tanam organik yang terbuat dari serbuk sabut kelapa. Karena bersifat organik, maka bisa dikatakan Cocopeat adalah media tanam yang ramah lingkungan. Cocopeat mempunyai daya serap air yang sangat tinggi, memiliki pH antara 5-6,8 dan cukup stabil, sehingga baik untuk pertumbuhan perakaran. Dalam penggunaannya, biasanya Cocopeat dicampur dengan media tanam lain seperti sekam bakar dengan perbandingan 50:50.

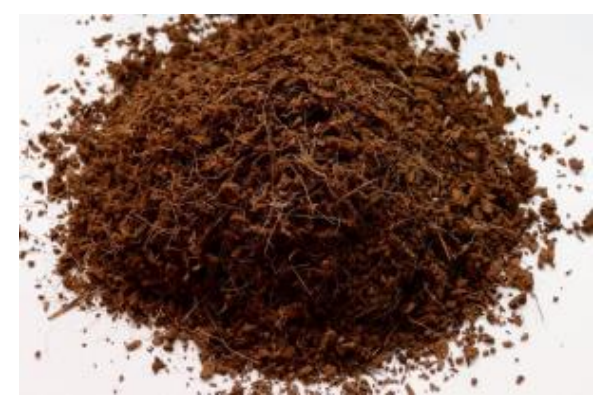

Gambar 7. Penggunaan Cocopeat dalam budidaya hidroponik (Lingga, 1994).

\section{c. Hydroton}

Hydroton (Gambar 8) merupakan media tanam hidroponik yang terbuat dari bahan dasar lempung yang dipanaskan, berbentuk bulat dengan ukuran bervariasi antara $1 \mathrm{~cm}-2,5$ $\mathrm{cm}$. Dalam bulatan-bulatan ini terdapat pori-pori yang dapat menyerap air (nutrisi), sehingga dapat menjaga ketersediaan nutrisi. Hydroton memiliki $\mathrm{pH}$ netral dan stabil. Dengan bentuk yang bulat (tidak bersudut), maka dapat mengurangi resiko merusak akar, dan ruang antar bulatan-bulatan ini baik untuk ketersediaan oksigen bagi akar. Hydroton dapat dipakai berulang-ulang, cukup dicuci saja dari kotoran/lumut/alga jika akan digunakan untuk penanaman selanjutnya (Lingga, 1994). 


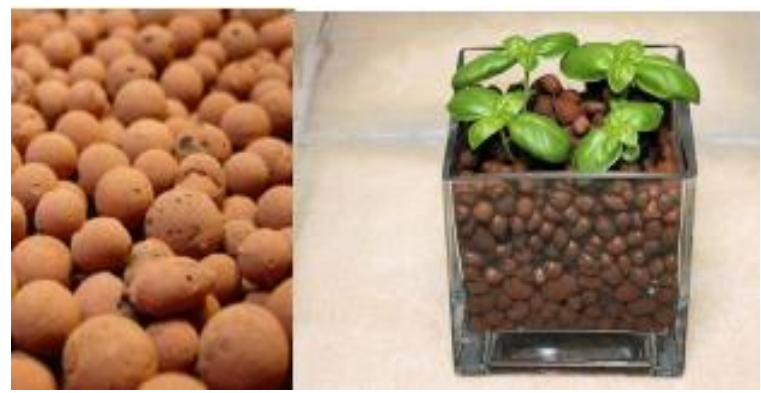

Gambar 8. Penggunaan Hydroton dalam budidaya hidroponik (Lingga, 1994)

\section{d. Sekam bakar}

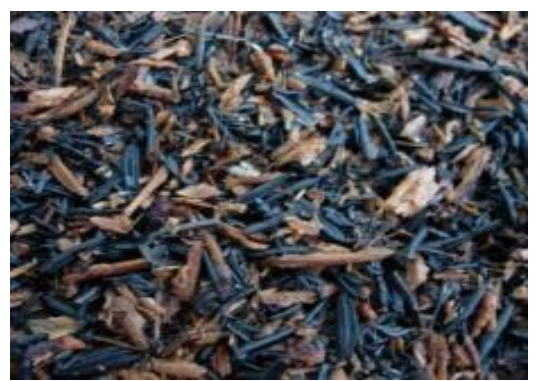

Gambar 9. Penggunaan sekam bakar dalam budidaya hidroponik (Lingga, 1994)

Sekam bakar (Gambar 9) merupakan salah satu media tanam yang sering digunakan tidak hanya untuk budidaya hidroponik saja, tetapi juga untuk budidaya tanaman dalam pot. Media tanam ini mudah didapat dan harganya sangat ekonomis. Sekam bakar memiliki daya ikat air dan aerasi yang cukup bagus. Merupakan media tanam organik, sehingga ramah lingkungan, $\mathrm{pH}$ netral, sehingga baik untuk perakaran tanaman. Dalam penggunaannya pada budidaya hidroponik, sekam bakar sering dicampur dengan Cocopeat (Lingga, 1994).

\section{e. Perlite}

Perlite (Gambar 10) merupakan media tanam yang dibuat dari batuan silika yang dipanaskan pada suhu tinggi. Perlite memiliki aerasi yang bagus, $\mathrm{pH}$ netral dan bobot yang sangat ringan (mirip busa/styrofoam). Perlite memiliki daya serap air cukup baik sehingga baik untuk perakaran. Dalam penggunaannya, biasa dicampur dengan media tanam lain seperti Cocopeat atau Vermiculite dengan perbandingan tertentu (Lingga, 1994).

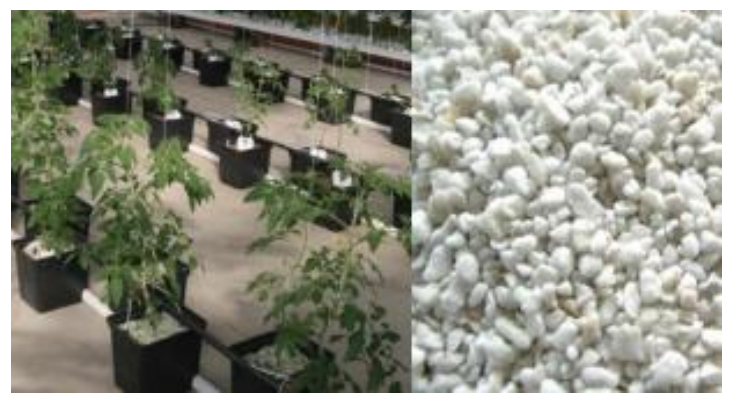

Gambar 10. Penggunaan Perlite dalam budidaya hidroponik (Lingga, 1994) 


\section{f. Vermiculite}

Vermiculite (Gambar 11) memiliki sifat hampir sama dengan Perlite, terbuat dari batuan yang dipanaskan pada suhu tinggi. Tetapi Verculite memiliki daya serap air lebih tinggi dan bobot lebih berat dari Perlite. Dalam penggunaannya, biasa dicampur dengan dengan Perlite dengan perbandingan tertentu (Lingga, 1994).

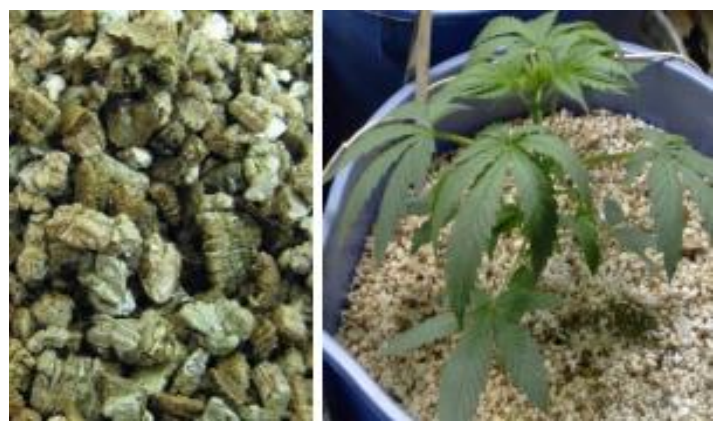

Gambar 11. Penggunaan Vermiculite dalam budidaya hidroponik (Lingga, 1994)

\section{g. Pasir}

Pasir (Gambar 12) dapat digunakan untuk pembenihan tanaman pantai dan pegunungan, seperti kelapa dan biji kacang.

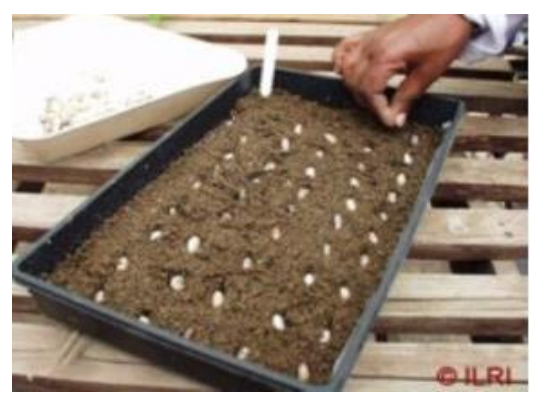

Gambar 12. Penggunaan pasir dalam budidaya hidroponik (Lingga, 1994)

\section{h. Kerikil}

Kerikil (Gambar 13) dapat digunakan untuk penanaman di dalam rumah kita jika ingin menambah kesan keindahan interior rumah, yang dapat ditanam dengan media kerikil hanya tanaman yang tahan terhadap air atau kebutuhan airnya tinggi.

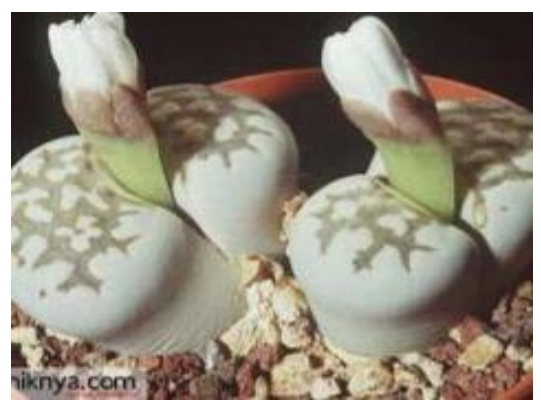

Gambar 13. Penggunaan kerikil dalam budidaya hidroponik (Lingga, 1994) 


\section{i. Serbuk kayu}

Serbuk kayu (Gambar 14) dapat digunakan untuk tanaman yang memerlukan kelembaban yang tinggi, misalnya jamur.

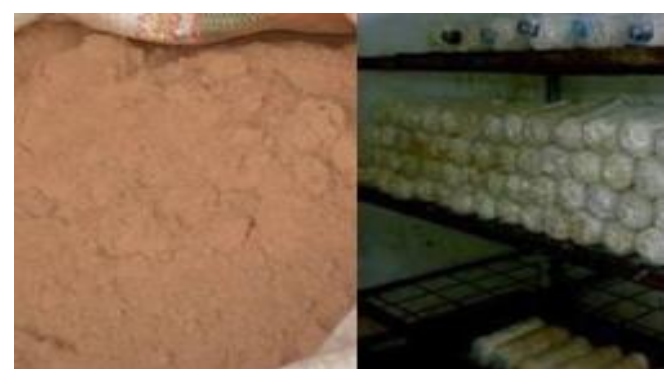

Gambar 14. Penggunaan serbuk kayu dalam budidaya hidroponik (Lingga, 1994)

\section{METODE PENGABDIAN}

\section{Waktu dan tempat kegiatan pengabdian}

Perancangan alat teknologi hidroponik mulai dilakukan sejak Tanggal 16 September 2017, sedangkan sosialisasi pelaksanaan kegiatan PPM Iptek tentang perancangan dan pemanfaatan teknologi Hidroponik Vertikal Hidro 40 Hole bagi Karang Taruna Tri Tunggal di Desa Talang Pauh Kecamatan Pondok Kelapa Bengkulu Tengah telah dilaksanakan pada hari Sabtu Tanggal 7 Oktober 2017.

\section{Alat dan bahan yang digunakan}

Alat dan bahan pembuatan hidroponik vertikal hidro 40 hole adalah Pompa hidroponik, Paralon $\mathrm{d}=0,5$ inc, Netpot $5 \mathrm{~cm}$, Female konektor 0,5 inc, pH meter ATC, Rockwool cultiline, Tutup paralon $\mathrm{d}=0,5$ inc, Nutrisi hidroponik, Bibit hidroponik, Kabel konektor, Fiber untuk wadah air vertikal hidro, dan Toolkit hidroponik.

\section{Perancangan peralatan teknologi hidroponik vertikal hidro 40 hole}

Prototipe peralatan teknologi hidroponik vertikal hidro 40 hole secara keseluruhan akan dirancang seperti Gambar 15 di bawah ini.

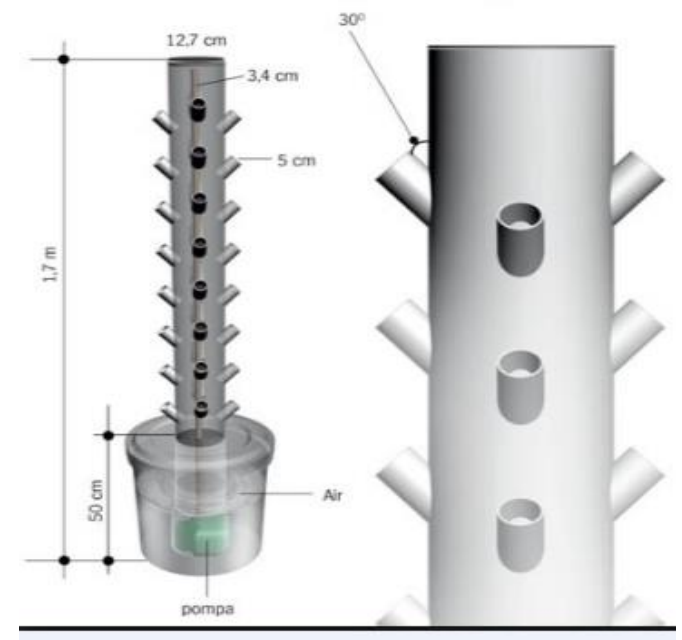

Gambar 15. Model alat teknologi hidroponik vertikal hidro 40 hole (Rahma, 2015) 


\section{HASIL DAN PEMBAHASAN}

\section{Perancangan pipa tempat netpot}

Pipa paralon dengan diameter 6,5 inc sepanjang 1 meter dibuat lubang sebagai tempat netpot. Jarak antara netpot adalah $5 \mathrm{~cm}$, baik ke arah atas bawah maupun ke arah kari kanan. Pada bagian atas pipa dipasang dop sebagai penutup pipa. Perancangan pipa tempat netpot ditunjukkan pada Gambar 16 di bawah ini.
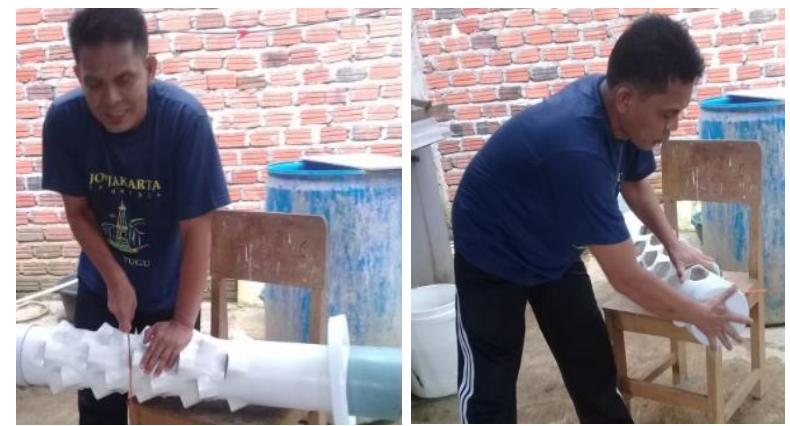

Gambar 16. Pembuatan lubang tempat netpot dan pemasangan dop pipa

Batas antara pipa dengan tutup wadah nutrisi dan air hidroponik dilem menggunakan lem pipa PVC agar tidak lepas pada saat diputar, seperti ditunjukkan pada Gambar 17.

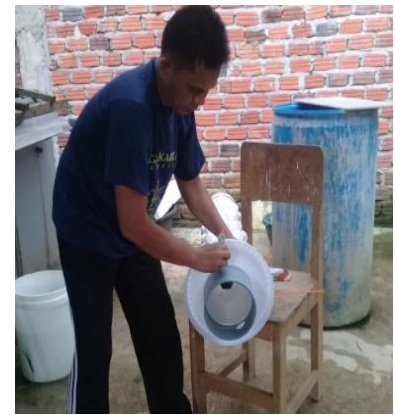

Gambar 17. Pengeleman batas pipa dengan tutup wadah nutrisi dan air hidroponik

Langkah selanjutnya adalah menyiapkan wadah nutrisi dan air hidroponik diisi dengan air sebanyak 20 liter, dicampur dengan nutrisi (pupuk) cair dengan perbandingan 1 cc/liter. Setelah proses pencampuran, campuran air dan nutrisi diaduk agar terlebih dahulu agar kedua bahan tercampur dengan merata. Langkah tersebut ditunjukkan pada Gambar 18 .
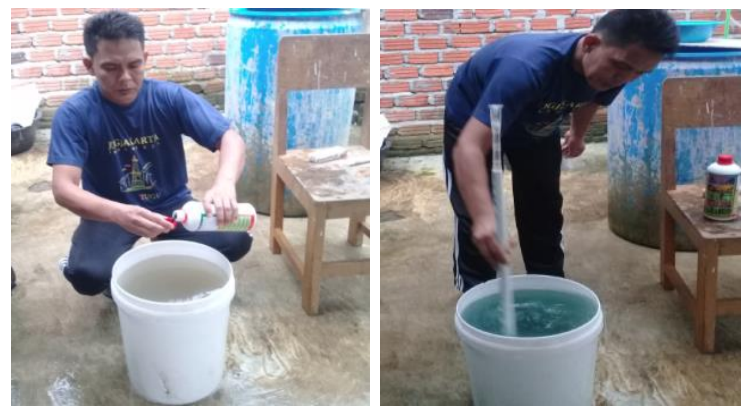

Gambar 18. Pemberian nutrisi (pupuk) serta proses pengadukan 
Langkah selanjutnya adalah pemasangan semua komponen seperti pompa akuarium, pemasangan pipa 0,5 inc untuk menyambung ke sprayer.
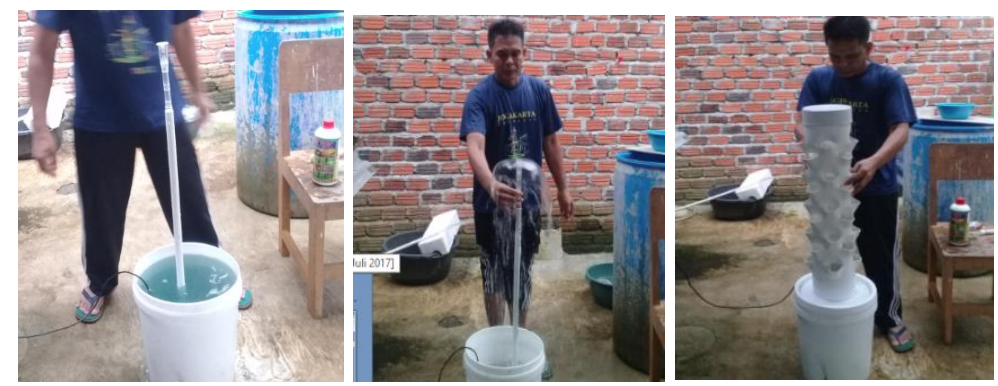

Gambar 19. Pemasangan seluruh komponen teknologi hidroponik

\section{Penyemaian bibit tanaman hidroponik}

Penyemaian bibit tanaman hidroponik dalam kegiatan PPM Iptek menggunakan media tanam rockwoll. Rockwoll dipotong disesuaikan dengan besarnya netpot. Untuk memudahkan penempatan bibit ke dalam netpot, digunakan ujung dari lidi dengan tujuan agar bibit tidak berserakan di tepi rockwoll. Pada Gambar 20 diperlihatkan proses penyemaian bibit serta bibit yang telah tumbuh berumur 2 minggu.
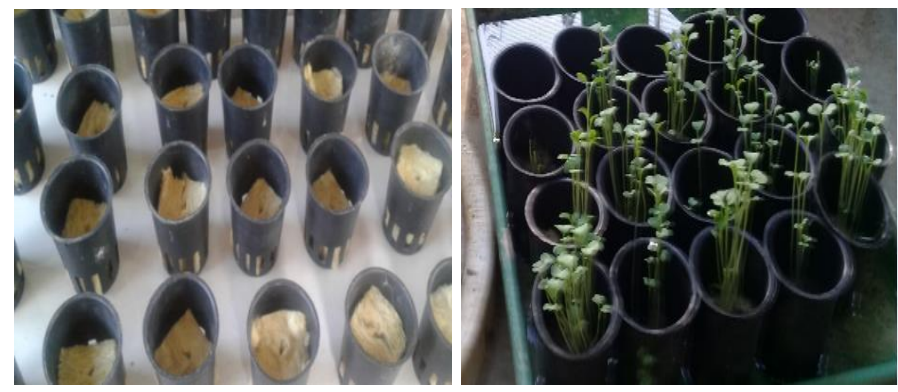

Gambar 20. Penyemaian bibit dan bibit tanaman hidroponik berumur 2 minggu

\section{Sosialisasi program}

\section{a. Pemanfaatan peralatan teknologi hidroponik vertikal hidro 40 hole}

Bentuk sosialisasi dan pemanfaatan peralatan teknologi hidroponik vertikal hidro 40 hole teknologi lubang resapan biopori pada kegiatan PPM Ipteks pada Karang Taruna Tri Tunggal adalah dengan menanam bibit sayuran yaitu sawi dan bayam. Pada Gambar 21 Tim Pengabdian PPM Iptek sedang memberikan penyuluhan tentang perancangan dan pemanfaatan teknologi Hidroponik Vertikal Hidro 40 Hole bagi Karang Taruna Tri Tunggal di Desa Talang Pauh Kecamatan Pondok Kelapa Bengkulu Tengah telah dilaksanakan pada hari Sabtu Tanggal 7 Oktober 2017.

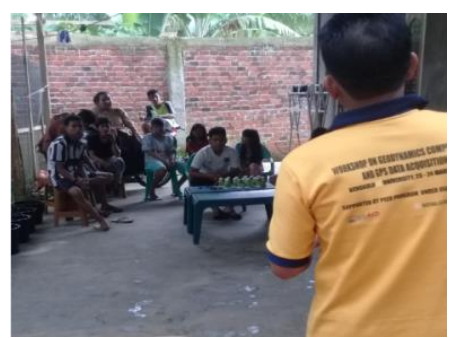

Gambar 21. Penjelasan tentang fungsi dan manfaat teknologi hidroponik 


\section{b. Partisipasi peserta dalam kegiatan pengabdian}

Pada pelaksanaan program sosialisasi pelaksanaan kegiatan PPM Iptek, para anggota Karang Taruna Tri Tunggal Desa Talang Pauh sangat berpartisipasi aktif dengan kegiatan ini. Partisipasi ditunjukkan dengan aktifnya anggota Karang Taruna dalam menghadiri kegiatan ini. Pada Gambar 22 di bawah, ditunjukkan para anggota Karang Taruna Tri Tunggal di Desa Talang Pauh Kecamatan Pondok Kelapa Bengkulu Tengah.

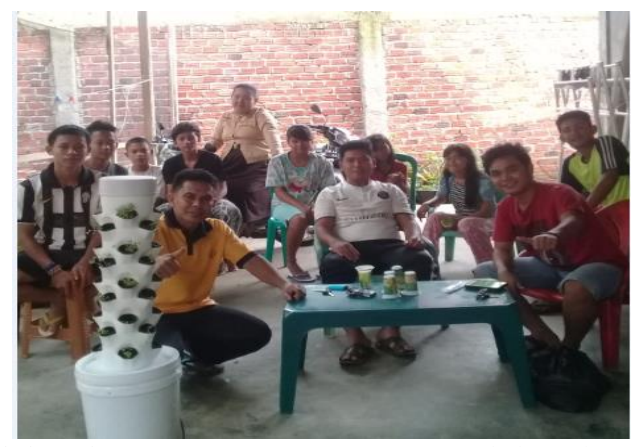

Gambar 22. Partisipasi anggota Karang Taruna dalam kegiatan pengabdian

\section{c. Penanaman bibit hidroponik}

Proses penanaman bibit merupakan pemindahan netpot yang telah ditumbuhi bibit sawi dan jenis tanaman lainnya ke dalam pipa paralon yang sebelumnya telah disediakan. Pada Gambar 23 diperlihatkan proses pemindahan bibit hidroponik yang telah berumur 2 minggu dan pertumbuhannya pada umur 21 hari.
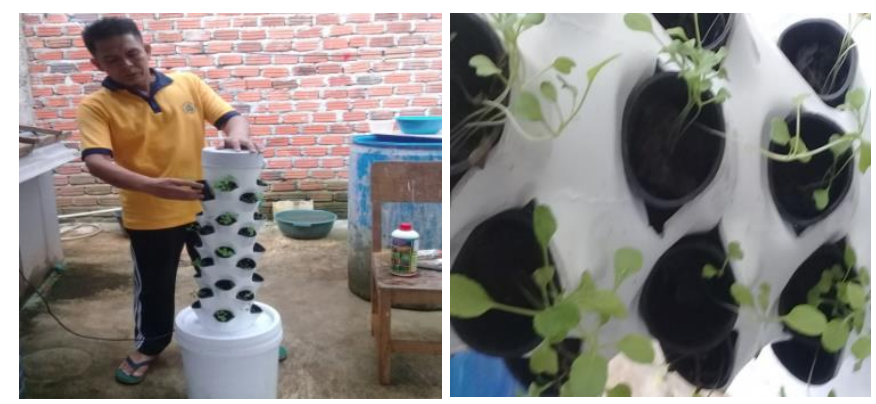

Gambar 23. a. Penanaman bibit hidroponik b. Tanaman hidroponik umur 21 hari

\section{KESIMPULAN DAN SARAN}

\section{Kesimpulan}

Dari kegiatan program kegiatan PPM Iptek yang telah dilaksanakan, dapat disimpulkan antara lain:

1. Para anggota Karang Taruna Tri Tunggal dapat memahami teknologi hidroponik vertikal hidro serta jenis hidroponik lainnya.

2. Para anggota Karang Taruna Tri Tunggal dapat merancang dan memanfaatkan teknologi hidroponik vertikal hidro sebagai salah satu upaya terobosan teknologi tepat guna pedesaan dalam melengkapi kebutuhan sayuran dan buah-buahan untuk skala rumah tangga. 


\section{Saran}

Setelah selesai program kegiatan PPM Iptek, diharapkan agar pemerintah desa dan pemerintah kecamatan dapat melanjutkan sosialisasi dari teknologi hidroponik untuk jenisjenis lainnya serta untuk skala yang lebih luas lagi.

\section{DAFTAR PUSTAKA}

Anas, D.S, 2013, Bahan Ajar Mata Kuliah Dasar-dasar Hortikultura, Departemen Agronomi dan Hortikultura, Fakultas Pertanian IPB: Bogor.

Lingga, P, 1994, Hidroponik Bercocok Tanam Tanpa Tanah, PT. Penebar Swadaya: Jakarta.

Mas'ud, H, 2009, Sistem Hidroponik dengan nutrisi dan media tanam berbeda terhadap pertumbuhan dan hasil selada, Media Litbang Sulteng, 2.

Rahma, P.P, 2015, Pengaruh tingkat EC (electrical conductivity) terhadap pertumbuhan tanaman sawi (Brassica juncea L.) pada sistem aeroponik vertikal, Jurnal Agro Fakultas Sains dan Teknologi UIN Sunan Gunung Djati, 2.

Syamsu, I.R, 2014, Pemanfaatan lahan dengan menggunakan sistem hidroponik, Jurnal Fakultas Pertanian Universitas Tulungagung, 1(2).

Triosa, A, 2016, Pengaruh jenis media tanam hidroponik terhadap pertumbuhan vegetative tanaman mentimun (Cucumis sativus L), Jurnal Pendidikan Eknomi Universitas Palangkaraya, 1(2).

-------, 2014, Data Monografi Desa Talang Pauh, Bengkulu Tengah: Bengkulu. 